\title{
EXPLORING MULTI-CRITERIA DECISION ANALYSIS METHOD AS A TOOL TO CHOOSE REGIONAL AIRPORT HUBS WITHIN AFRICA
}

\author{
B. SSAMULA \\ Built Environment, CSIR, South Africa.
}

\begin{abstract}
The aviation industry in the African region, in order to compete with the global market, is exploring and actively pursing expansion either through strategic alliances or by adopting the hub and spoke (H\&S) network development. Hubbing has the major benefits of consolidating passengers, thus increasing frequency of travel while increasing accessibility and improving the economies of scale to operate the service. The African region is vast and is characterised by sparse passenger demand; therefore, the decisions made in locating airports as hubs pose a challenge. This paper aims to explore the use of the multi-criteria decision analysis (MCDA) tools as a method of choosing hub airports. The reason why the MCDA tools are most appropriate is because choosing a hub airport is a complex decision which has to take into account various issues like: network costs, infrastructure costs, security, economic viability, safety, passenger travel time expenditure, etc. The various tools, processes and methodologies used in decision making theory are explored and applied in order to choose hub airports with the lowest transport costs in an efficient H\&S network. The major findings in this study show that because Africa has a sparse network, with a few role players, the choice in hub location options relies greatly on the cost of routing passengers through the hub airport. MCDA is shown to be a useful tool whose only limitation is maintaining the uniformity of weighting the criteria for the whole region.

Keywords: Africa aviation, airports, decision analysis, hub location, network design.
\end{abstract}

\section{AFRICA AS A SPARSE REGION}

Africa is a large continent of 30 million $\mathrm{km}^{2}$, with dimensions three times the size of Europe and distances from the south to the north of about $8,000 \mathrm{~km}$. Although the population of the continent is over 860 million, the average population density of Africa is 28 inhabitants per $\mathrm{km}^{2}$, which falls below the world's average population density of 44 persons per $\mathrm{km}^{2}$, thus defining the continent as a sparsely populated region.

In 2002, Africa's population comprised $13 \%$ of the world's total, with Africa's air passenger traffic contributing only $4.1 \%$ to the world's total air passenger traffic, making it the smallest region for air services worldwide [1]. The passenger data used in this study show that the annual number of air trips per inhabitant in Africa is equal to only 0.14 . The low demand for air travel within the region is due to the fact that it is an expensive unaffordable means of travel.

Furthermore, the load factor, which is the ratio of the revenue passenger kilometres (RPK) to the available seat kilometres (ASK), is one of the critical determinants of profitability in relation to the breakeven load factor. Fig. 1 shows that the African region has the lowest load factor at $62.56 \%$, compared with other regions of the world. The Far East and Pacific regions have relatively high load factors, averaging $76.32 \%$. The low load factors are a reflection of the scanty routes in the African region. The routes are scanty because of the much higher air fares compared with those in other regions of the world and because of a relatively poor population, hence the sparse travel demand on the continent.

Even though Africa shows great potential with initiatives like the open skies initiative adopted in the Yamoussoukro Decision, under the auspices of the African Union and New Partnership for Africa's Development (NEPAD), the challenge will be to make air travel affordable and accessible, so as to improve trade and tourism through the economic impact of air transport on countries.

(C) 2010 WIT Press, www.witpress.com

ISSN: 1743-7601 (paper format), ISSN: 1743-761X (online), http://journals.witpress.com DOI: $10.2495 /$ SDP-V5-N2-83-97 
1.1 Hub and spoke network design

Button et al. [2] state that in order to minimise costs and keep airfares down, airlines need to keep aircraft in the air for the longest possible time to achieve the highest possible load factor, and to coordinate their aircraft, crew and maintenance schedules. To achieve this, many airlines operate hub and spoke (H\&S) networks which entail consolidating traffic from a diverse range of origins, destined for a diverse range of final destinations at hub airports.

$\mathrm{H} \& \mathrm{~S}$ networks involve the collection of passengers from their origin ( $i$ ), transferring them through hubs nodes ( $k$ and $l$ ) and then distribution of passengers to their destination node $j$ as illustrated in Fig. 2.

The advantages of hubbing for routes with low passenger demand are very apparent. A traditional airline would not serve these routes because the operating costs needed to meet the low demand make them unprofitable. Accessibility within the continent would actually increase with hubbing

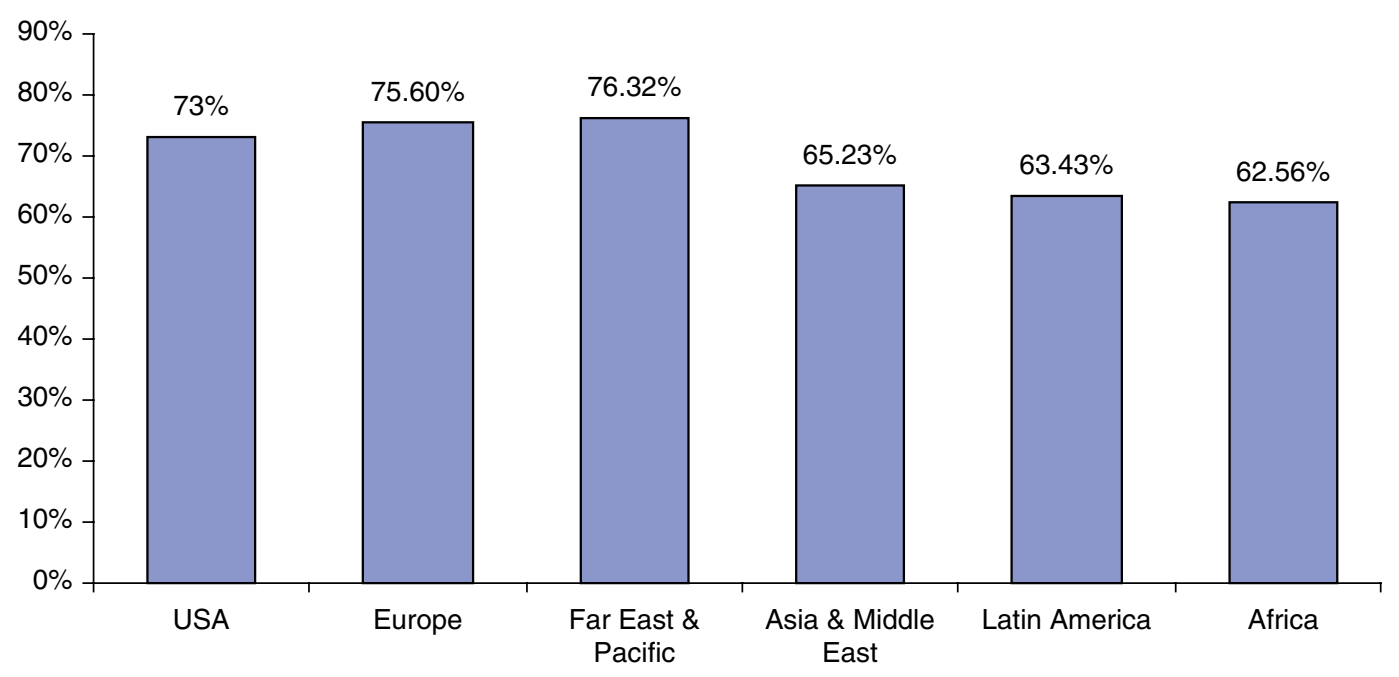

Figure 1: Load factors for world regions. Source: Chingosho [1].

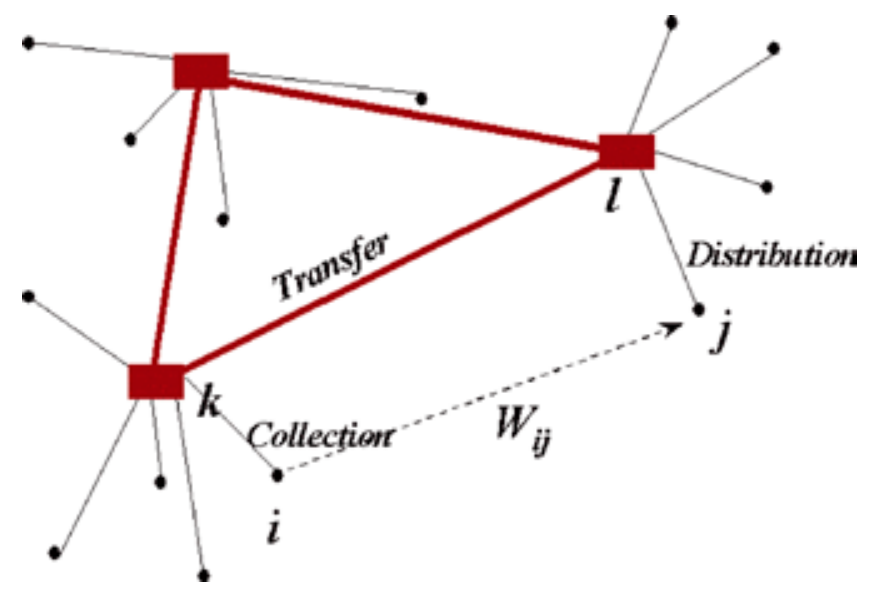

Figure 2: Schematic representation of the hub and spoke network design. Source: CMISRO [3]. 
due to the fact that the flight frequency of the airlines would increase, which is an advantage to users of the service because they have more options. The hub network allows flexibility of planning and operations for the service provider, with adequate utilisation of aircraft on routes with reasonably high load factors, yielding profitability in a market of scarce passenger demand [4].

The methodology involved in the design of H\&S network involves, first, locating the hub airports through which all the flow will pass. Once the hubs have been located, the nodes are allocated to the hubs using single assignment to the closest hub. Thereafter, the pattern of flow for the network is established and the passenger numbers along each link are calculated. The network is then costed by calculating the cost of transferring all the passengers from their origins to their destinations through the hub links.

The crucial step in H\&S network design is the hub location problem. Boland et al. [5] define the hub location problem as one concerned with creating H\&S networks, which involves locating hubs and assigning non-hub nodes to hubs with the objective of minimising transportation costs across the network. This determines the cost effectiveness of the H\&S network as compared to point-to-point travel. Operational researchers have carried out various studies to try and solve the hub location problem in the most practical, meaningful and realistic way for airlines. For the purpose of this study, the location of the hub airports is the decision that needs to be made using the multi-criteria decision analysis (MCDA) process.

With Africa's air network characteristic of low passenger demand and the vastness of the continent, designing a hub network will be a challenge. This paper focuses on simplifying one of the steps entailed in designing an H\&S network using the MCDA method for the African region as a way to foster the development of air transport.

This paper will define the H\&S network design elements that are crucial for sparse networks. Thereafter, the MCDA process and methodology will be introduced and applied to the hub location procedure. An evaluation of the criteria will be carried out to highlight how the MCDA method can simplify a complex decision making process in the H\&S network design methodology.

\subsubsection{Importance of hub location}

Hubs are defined as collection points that serve the purpose of consolidating traffic flow. The concentration or consolidation of flow can reduce movement costs (i.e. transportation or transmission) through economies of scale, even though the distance travelled may increase as stated by Campbell [6]. Hubs are usually found within air networks, mail delivery systems and in telecommunications.

Schnell and Huschelrath [7] suggest that hubs can be defined in two general ways: (1) denoting whether an airport represents a hub within a carrier-independent system of air transport (i.e. airport level) and (2) denoting its role within a carrier-specific network (i.e. airline level). In the analysis of hubbing, the definition of what constitutes a hub becomes crucial. For the purposes of this study, a hub airport will be defined at airport level, based on route structure, i.e. its function as a distribution point for air travel to and from its surrounding catchment area, with connecting services, irrespective of the number of originating passengers and airlines serving it.

\subsubsection{Limitations of the study}

1. Technicalities that exist in the airline industry as a business, which include regulatory components of service agreements, operational constraints such as degrees of freedom permitted, competition, available time slots, security and pollution, will not be included.

2. The network cost results of this study are neither deemed to be an accurate representation of the transportation costs nor realistic for airlines in the region. This is purely an academic exercise and therefore the real potential of this exercise is to use the results to develop a methodology to identify 
cost-effective criterion to determine the various MCDA alternatives. This study can be applied to real airline operations data in assessing hub network optimisation strategies using MCDA.

3. The environmental costs of hub networks as explained by Morrell and $\mathrm{Lu}$ [8] will not be taken into consideration when calculating the environmental costs resulting from an H\&S network design.

4. The airline service being considered is a traditional passenger airline which transports its passengers to their destinations at the minimum frequency needed to meet existing demand.

\section{MULTI-CRITERIA DECISION ANALYSIS}

Tecle and Duckstein [9] define MCDA as a vast field of study which includes decision making in the presence of two or more conflicting objectives and/or decision analysis processes involving two or more attributes. The general objective of MCDA is to assist a decision maker or a group of decision makers to choose the best alternative from a range of alternatives in an environment of conflicting and competing criteria. The methodology of decision analysis provides a framework to combine traditional techniques of operations research, management science and systems analysis with professional judgments and values in a unified analysis to support decision making as stated by Pieterson [10].

Decision analysis focuses on aspects fundamental to all decision problems namely:

1. A perceived need to accomplish some objectives.

2. Several alternatives, one of which must be selected.

3. The consequences associated with alternatives are different.

4. Uncertainty usually about the consequences of each alternative.

5. The possible consequences are not all equally valued.

In recent years, several methods have been proposed to deal with MCDA problems. Belton and Stewart [11] highlighted the value function method as one of the several methods most suited for complex problems. Furthermore, Belton and Stewart [11] state that value function methods are some of the more widely applied MCDA methods and have benefited from the long-standing interests of psychologists, engineers and management scientists who have been nurtured through a continuing awareness of behavioural and social issues as well as the underlying theory. The methods are able to deal with complex issues, can accommodate the involvement of multiple stakeholders and allow processes to be facilitative and transparent. Value function methods can assist in the problem formulation phase and in informing stakeholders about the decision processes [12].

The value function method synthesises assessment of the performance of alternatives against individual criteria, together with inter-criteria information reflecting the relative importance of the different criteria, to give an overall evaluation of each alternative indicative of the decision-makers' preference. The reason why this method is the most appropriate is because choosing a hub airport is a complex decision which has to take into account various issues like: network costs, infrastructure costs, security, economic viability, safety, passenger travel time expenditure, etc., all of which have different and varied impacts and implications.

\subsection{Methodology}

The MCDA process is used because this approach uses several criteria, in which the analyst aims at establishing comparisons on the basis of the evaluation of the alternatives according to several criteria. In an approach using a single criterion, the analyst seeks to build a unique criterion taking into account all the relevant aspects of the problem. The methodology used in this paper is classified into four steps. These steps are outlined below. 
1. Structuring the decision problem: This involves the generation of alternatives and the specification of objectives.

2. Assessing possible impacts of each alternative: In this step, the analyst determines the impact of each alternative. If it were possible to precisely forecast impact, we could associate one consequence with each alternative. Then the evaluation of alternatives would boil down to a choice of the best consequence, preferably based on research.

3. Determine preferences (values) of decision makers: This step, unique to decision analysis, involves the creation of a model of values/preferences to evaluate each of the alternatives.

4. Evaluate and compare alternatives: Once a decision problem is structured, the magnitude and the associated likelihoods of consequences determined, and the preference structure established, the information must be synthesised in a logical manner to evaluate the alternatives.

\section{APPLYING MCDA TO THE HUB AIRPORT LOCATION}

3.1 Decision problem: hub location analysis

Locational analysis is a procedure in operational research used to locate the hubs and route flow via the hubs in an H\&S network system. The two systems defined by O'Kelly and Bryan [13] are:

- A delivery system, in which the decision-maker positions the facilities and determines the rules of allocation to the centres.

- A user-attracting system, where the facility is located by one agent but the allocation decisions are decentralised and the planner has to make some reasonable guesses as to how the public will make use of the facilities.

There are various factors, pointed out by Schnell and Huschelrath [7] that influence the likelihood of an airport becoming a hub. Some of these factors are:

- climatological characteristics of the location,

- geographical location and topographical surroundings,

- market size of the airport,

- inhabitants' income,

- level of development of business and leisure centres to increase the attractiveness of the airport,

- potential of the airport to increase its capacity when there is congestion,

- number of flights operated,

- number of destinations served,

- number of gates available at the airport.

Africa faces the dilemma of not having many international airports with the capacity, demand, market size and infrastructure for hubbing. This is due to the low levels of income in most countries and the expense associated with air travel and its infrastructure. As discussed in Section 1, the decision to be made is the evaluation of various criteria to determine and solve the hub airport location problem, with the aim of minimising network costs.

\section{ASSESSING RESEARCH-BASED IMPACT OF DIFFERENT CRITERIA}

The criteria that are used to assess the various hub airport location have been summarised and categorised in Table 1. 
Table 1: Criteria for MCDA.

\begin{tabular}{lll}
\hline Functional criteria & Operational criteria & Locational criteria \\
\hline Airport infrastructural capacity & Passenger demand & Shortest paths \\
Flow thresholds & N-H costs & Centrality of the hub \\
& Network costs & \\
\hline
\end{tabular}

\subsection{Functional criteria}

This criterion analyses the elements that influence the functioning of an airport as a hub. Most of the challenges of airports that act as hubs include the ability of the airport to serve the additional demand.

\subsubsection{Airport infrastructural capacity}

CMISRO [3] defines airport capacity as the limit on the amount of flow being collected by non-hub nodes from hub nodes. Capacity is important at hub airports because of the congestion that can arise at such airports due to the limitations in facilities (in terms of gates, runways and hangars) that are realised when an airport becomes a hub. Schnell and Huschelrath [7] state that for airlines there is a restriction on expansion at congested hub airports due to lack of slots in which planes can land. As a result, there is reduced flexibility on scheduling, which increases susceptibility to delays in emergency situations.

\subsubsection{Flow thresholds}

The CMISRO [3] defines flow thresholds as the minimum flow that is needed on some or all of the links. The flow thresholds for each of these hubs could be taken into consideration, so that the flow carried would correspond to the capacity of the airport to serve as a hub. Some of these elements could be defined by:

- Number of airlines operating: This reflects the airport's operational capacity in terms of gates, slots, baggage-handling processes and aircraft turnaround time.

- Airport passenger capacity: This assesses the ability of an airport to accommodate and serve high passenger numbers currently, based on current hubbing functionality and role, either geographically or operationally, to ease the transition into becoming a hub. Airport capacity is also of concern when there is need to consider an alternative route or a direct flight between $i$ and $j$ if this will cause the capacity of the hub airport to be exceeded when flow is consolidated.

\subsection{Locational criteria}

Locational criteria define the elements of the airport in terms of its location within the region and the $\mathrm{H} \& \mathrm{~S}$ network, with specific focus to the impact on sector distances.

\subsubsection{Shortest paths}

Generally, as distances increase, the costs per passenger increase as well, due to the increasing operating costs incurred with higher aircraft utilisation costs in terms of depreciation, fuel and labour. This means that in order to ensure low operating costs, the sector distances flown should be kept as short as possible.

In this method, the allocation problem of collecting and distributing flow can be solved by finding the shortest path between each pair of nodes in the directed graph, allowing collection from any node 
to any hub, transfer between hubs and distribution from any hub to any node. Ssamula [14] proved that in route networks, the shortest path usually implies that the costs on the route are minimised, because of the ability to fly smaller aircraft which are cheap to operate on these routes. Fig. 3 defines the relationship between weekly costs per passenger and increasing sector distances for various aircraft types, with an annual passenger demand of 30,000. The relationship between distance and cost for a given aircraft is linear because depreciation, fuel and labour increase with flight time or distance, which is similar to the findings of Swan and Adler's study [15].

The general advantage of flying short routes is that a small fleet size is needed to operate the O-D pairs with both high and low passenger demand. Even when the frequency of flights increases with increasing passenger demand in the hub network, the fleet size will remain small because the flights are shorter [4].

\subsubsection{Centrality of the hub}

A procedure was performed by Topcuoglu et al. [16] to test for the cost benefits of locating a hub as centrally as possible within a cluster. It involved finding the geographical location of the mid-point using the latitude and longitude of all nodes in the cluster and then choosing the node that was nearest to the mid-point to act as a hub.

Klincewicz [17] used the clustering heuristics methodology as one of the methods for choosing hubs in the facility-location problem by dividing the area into clusters and the different airports were given indexes in terms of probabilities. It uses the principle that the airport in a cluster that is most suitable as a hub would be the airport with the shortest node-hub distances and the highest passenger demand cluster, making it a more effective way of optimising the movement of flow. Based on this methodology, Ssamula [4] applied the method and found that this method in which the emphasis is placed on the strategic location of the hub, leads to a reduction in both node-hub and hub-hub costs.

\subsection{Operational criteria}

The operational criterion includes the factors that influence airports' attractiveness as a hub based on elements that lower or optimise operational costs. These elements include passenger demand, node-hub cost analysis and network costs.

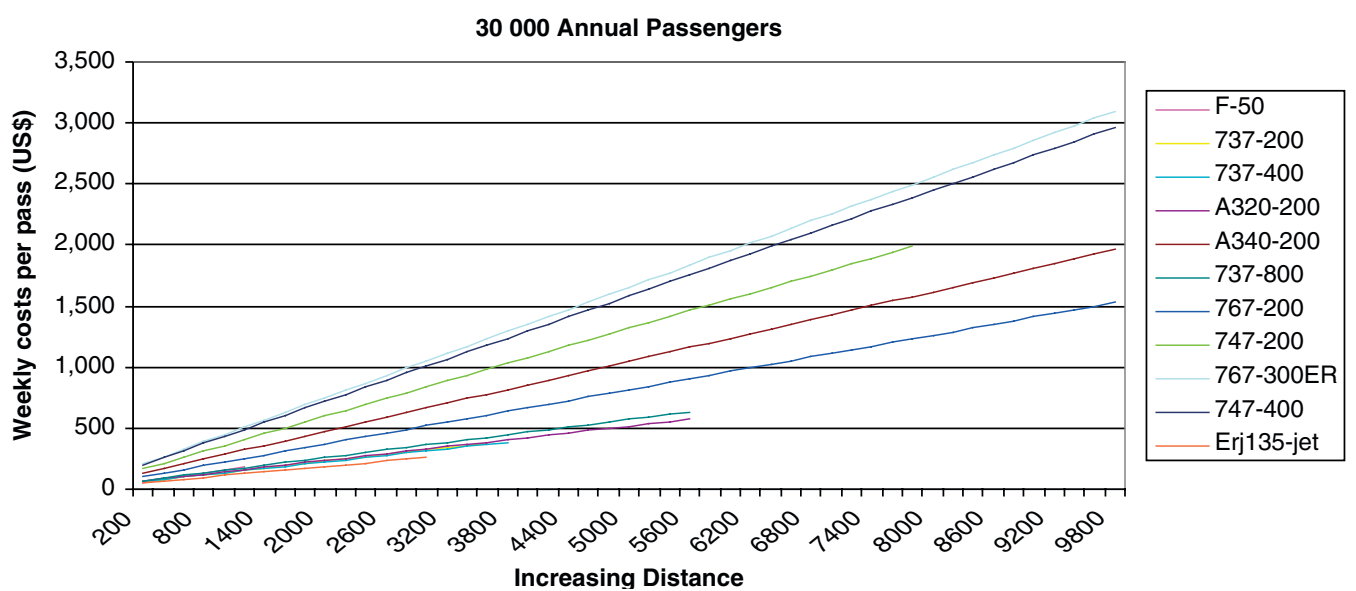

Figure 3: The linear increase of weekly operating costs with sector distance. 


\subsubsection{Passenger demand}

The general trend is that as passenger numbers increase, the benefits of economies of scale increase. This is because the costs per unit flow decrease exponentially as demand increases until they become constant. Doganis [18] states that, economies from route traffic density arise because the higher seat load factors lower the costs per passenger mile.

Fig. 4 derived from an airline route costing study by Ssamula [4] confirms the exponential decrease of costs per passenger as the weekly passenger numbers increase on a 3,000-km route for the 11 different aircraft. The study also found that high passenger demand reflects the infrastructure capacity of the airport and economies-of-scale benefits on the node-hub links. Hubs chosen coincidentally have the highest passenger demand within the region. The high passenger demand lowers the nodehub costs because the aircraft fly at high load factors.

\subsubsection{Node-hub cost analysis}

The node-hub links in any hub network contribute more to network costs than the hub-hub links as determined by O'Kelly and Bryan [13] and confirmed by Ssamula [4] that node-hub costs contributed an average of about $56 \%$ to network costs. This is because the hub-hub links benefit more from the economies of scale gained from consolidated flow. This implies that since the node-hub portion of the journey is more costly, a strategy aimed at minimising the costs on the node-hub link needs to be explored. If the distances on the node-hub link can be minimised, the operating costs will be lower and this will encourage the use of smaller, cheaper short-range aircraft, which will minimise costs. In the study done by Ssamula [4] the node-hub cost analysis was used as a hub location methodology in trying to design an H\&S network. The method and the findings of that methodology are outlined below.

Fig. 5 represents the cost of transporting flow $\left(C_{i-n}\right)$ 'from' each node $\left(O_{i}\right)$. The total cost from node $i$ to each of the $n$ nodes in the network is summed in eqn (1). The nodes that have the cheapest costs of transporting flow from them are used as hub location options.

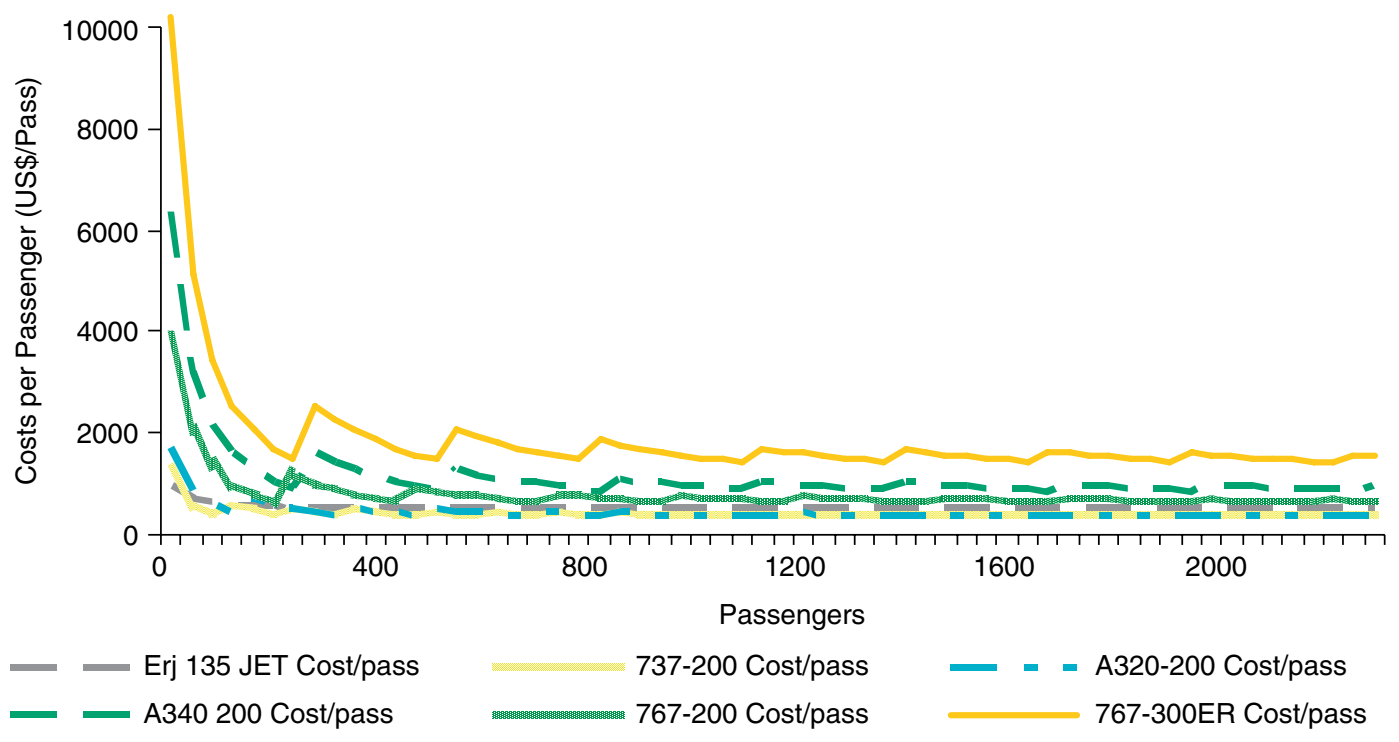

Figure 4: Exponential decrease of costs with increasing number of passengers. 


$$
O_{i}=\sum_{1}^{50} C_{i-n}=C_{i-1}+C_{i-2}+\cdots+C_{i-n}+C_{i-50} .
$$

The cheapest nodes from which to fly the passengers as hub options, in this method the cheapest hub nodes chosen coincidentally, had the highest passenger demand within the region.

Fig. 6 illustrates the calculation of the cost of transporting flow $\left(C_{n-i}\right)$ 'to' each node $\left(D_{i}\right)$. The total costs for all the nodes in the network were summed. The nodes that have the lowest costs to fly as destinations are used as hub location options.

$$
D_{i}=\sum_{1}^{50} C_{n-i}=C_{1-i}+C_{2-i}+\cdots+C_{n-i}+C_{50-i} .
$$

In this method, centrality of the hub nodes with the shortest total distances was found to be a commonality with the cheapest hub network design. The strategic location of the hubs was found to outweigh the economies of scale achieved through high traffic volumes.

\subsubsection{Network costs}

By definition, network costs mean the total costs of transporting passengers from their origin to their destination through the hubs. The costs are calculated as a product of the costs per unit flow and the

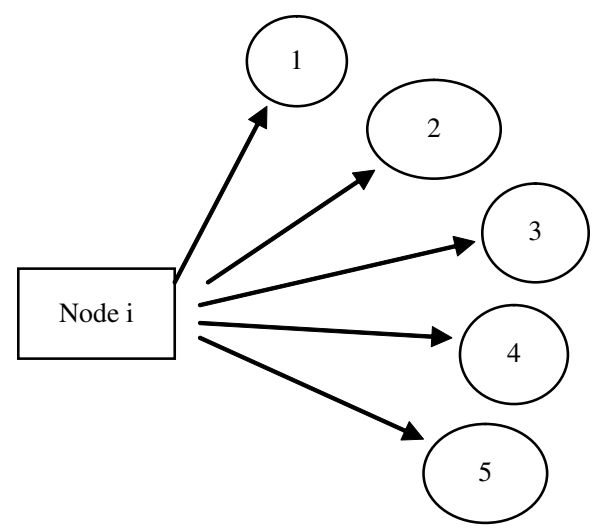

Figure 5: The cheapest hub to fly 'from'.

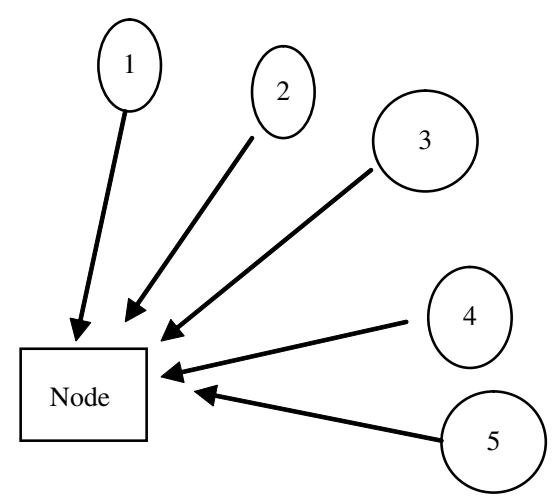

Figure 6: The cheapest hub to fly 'to'. 
flow along all the routes. An analysis of total network costs is crucial to find out which hub locations achieve lower costs on a larger scale. Ssamula [4] summarised some of the important design elements for optimum sparse $\mathrm{H} \& S$ network designing sparse networks as

1. The transmission flow costs which were found to be cheapest for hub location options which have high passenger demand.

2. The sector distance was also found to be crucial in lowering operating costs, in sparse markets, as smaller more efficient short-range aircraft can be operated.

3. Since sector distances are crucial in lowering costs the optimum number of hubs/clusters in sparse markets is determined by the distance threshold for the efficient aircraft.

4. Nodes are assigned more efficiently to the closest hub in order to lower node-hub costs by minimising $\mathrm{N}-\mathrm{H}$ links.

Even though many network cost equations exist in literature, for the purposes of this study, the equation that is used is developed from the uncapacitated single allocation $\rho$ hub median problem, using the quadratic optimisation problem with linear constraints of the hub location problem developed by O'Kelly and Bryan [13] and rewritten by Klincewicz [17]. This eqn (3) is used to calculate network costs for networks in which the hub capacity has no threshold and each node is allocated to a single hub to limit complexity. The equation used to calculate the network costs, is given as

$$
f(x)=\sum_{i} \sum_{k} X_{i k} C_{i k}\left(O_{i}+D_{i}\right)+\sum_{i} \Sigma_{k} X_{i k} \sum_{k} \sum_{m} X_{k m} C_{k m} W_{k m} .
$$

The first term in eqn (3) involves the calculation of the collection and distribution costs (node-hub movement); this part of the equation includes:

- $O_{i}$ and $D_{i}$ represent the total amount of flow originating and terminating at node $i$, since all those passengers have to undergo that leg of the journey regardless of their final origin or destination node.

- The factor $X_{i k}$ is the constraint that addresses the fact that all nodes go through at least one hub. It is represented as 1 if that node-hub movement occurs and as 0 otherwise.

- $C_{i k}$ represents the cost per passenger from node $i$ to the nearest hub, $k$.

- The second term in eqn (3) calculates the cost of moving the people who are travelling through the hubs $k$ and $m$.

- The factor $X_{i k}$ is represented as 1 if that node-hub movement occurs and as 0 otherwise.

- The factor $X_{k m}$ is represented as 1 if the hub-hub movement occurs for a given O-D path and as 0 otherwise. This means that only the passenger flow $W_{k m}$ that is determined by the $\mathrm{N}-\mathrm{H}-\mathrm{H}-\mathrm{N}$, $\mathrm{H}-\mathrm{H}-\mathrm{N}$ or $\mathrm{H}-\mathrm{H}$ movement is included in this part.

- $C_{k m}$ represents the cost per passenger on the $\mathrm{H}-\mathrm{H}$ links from hub $k$ to hub $m$.

4.4 Applying criteria to the evaluate the various alternatives

For purposes of this study, each of 50 countries is represented by one major international airport that is used as a node within the African network. All the international airports used in the database of the cost model were analysed. Special consideration was given to airports that are currently being used as hubs in these regions.

The continent was divided into four geographical regional clusters as shown in Fig. 7, based on the optimum number of hubs derived by Ssamula [4]. This process entailed generically assessing the optimal number of clusters to produce an efficient network. In order to find the optimum number of hubs for the network, virtual hubs are found at the centre of each cluster for a two-, three-, four- and five-cluster network. This systematic method is then used to analyse the effect of increasing the number of hubs on network costs illustrated in Fig. 8. Based on the total network costs, it appears that the optimum network for the continent would be either a four-hub network because it had the lowest costs. 


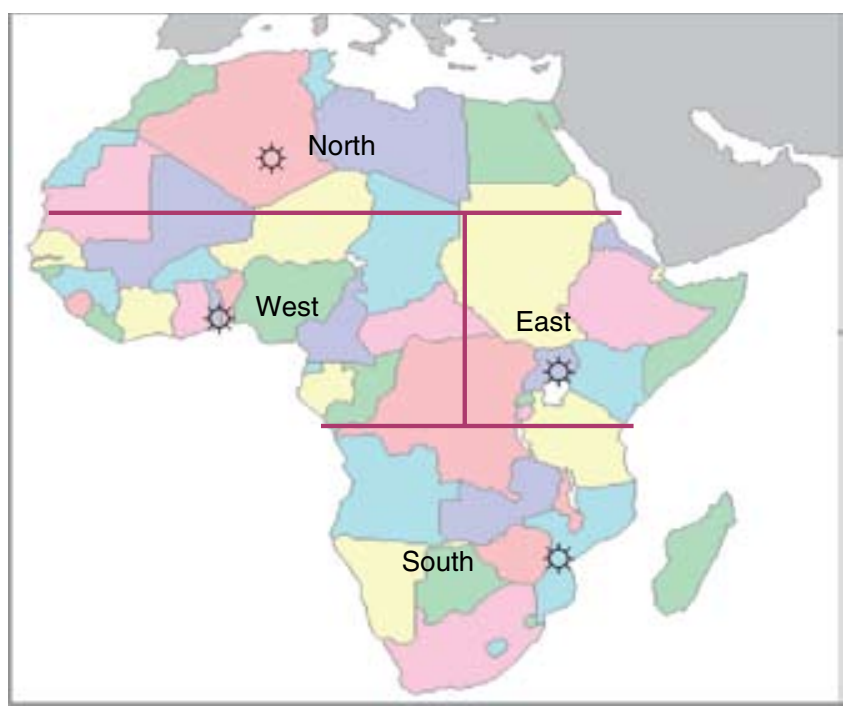

Figure 7: Four-cluster network.

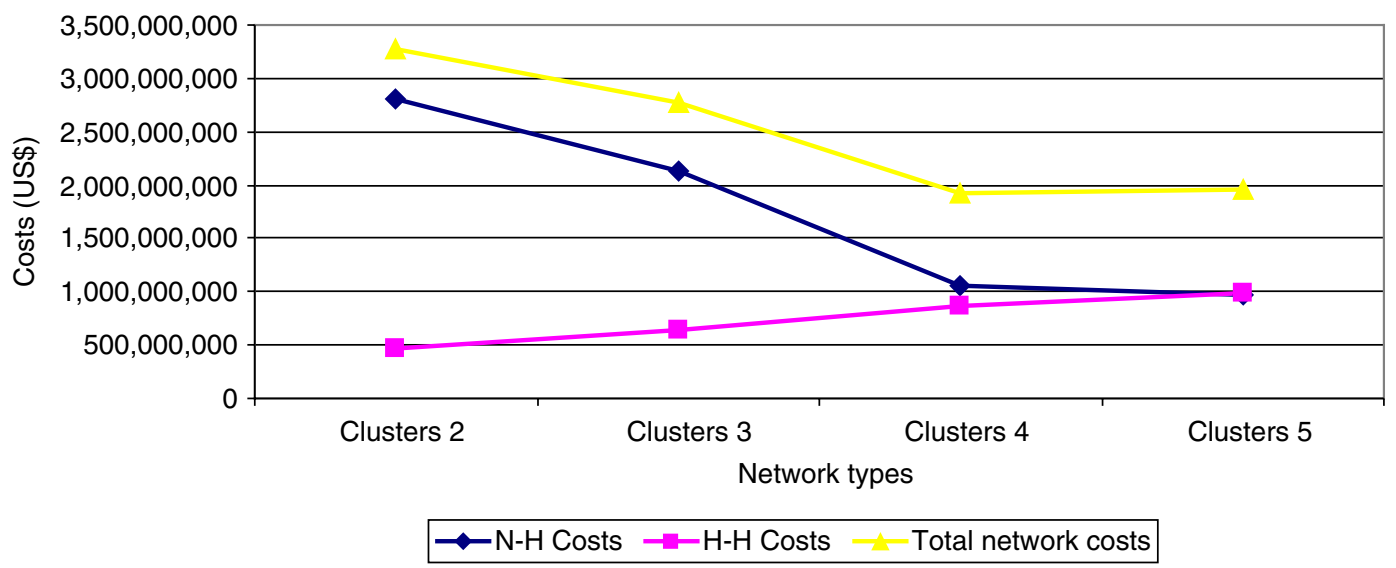

Figure 8: Cost variations as clusters increase in a network.

The region was then divided into four clusters which are also aligned with the existing Regional Economic Communities (RECs). The RECs listed in their specific regions illustrated in Fig. 7 are:

1. United Maghreb Union (UMA) in the north,

2. East African Community (EAC) or Common Market for Eastern Southern Africa (COMESA) in the east,

3. Economic Community for West African States (ECOWAS) in the west,

4. Southern African Development Community (SADC) in the south.

The various cost elements (cost per passenger) and the various alternatives used in MCDA process will be derived from the cost model developed by Ssamula [19]. This cost model calculates the operating costs incurred by flying along a specified route, and the database for this model contains Africa-specific data. The costs used are calculated by selecting the aircraft (chosen from 11 different aircraft types of varying capacity) most commonly used in Africa that produces the lowest operating costs for the route. 
4.5 Determining preference values for criteria

The parameters used to justify potential hub airport options for each criterion will be based on the hub airport locations that provide the criteria that have potential for lowering total network costs and reducing passenger travel time. The preference value, which determines how the criteria achieves its aim for each of the criteria, and the data source for the information are outlined in Table 2.

\subsection{Evaluation criteria}

The process of determining which nodes are chosen as the most suitable hubs is elaborated below.

1. An index of 1 is awarded to the airports within that cluster that meets the criteria, i.e. for highest passenger number $=1$.

2. The indexes for the rest of the airports within the row are calculated in proportion ratios of 1 to the index of the airport that met the criteria.

3. Indexes are calculated for each criterion and for each airport.

4. The airport with the highest index within the cluster becomes the most probable hub airport.

Table 2: Preference values and data sources for the criteria.

\begin{tabular}{|c|c|c|}
\hline Criteria & Preference value & Data source \\
\hline $\begin{array}{l}\text { Airport infrastructural } \\
\text { capacity }\end{array}$ & $\begin{array}{l}\text { The presence of adequate infrastructure in terms } \\
\text { of runways, gates and aprons to accommodate } \\
\text { a high frequency of flights is vital. This would } \\
\text { mean that minimum additional investment } \\
\text { would be needed when converting airports to hubs }\end{array}$ & $\begin{array}{l}\text { World Bank Data Query, } \\
\text { aircraft departures per } \\
\text { year, for the year } 2001\end{array}$ \\
\hline Flow thresholds & $\begin{array}{l}\text { Highest number of airlines operating currently, } \\
\text { this capacity can handle the extra flow }\end{array}$ & $\begin{array}{l}\text { Individual airport } \\
\text { information: world } \\
\text { airport data }\end{array}$ \\
\hline Passenger demand & $\begin{array}{l}\text { The presence of high passenger demand at an } \\
\text { airport implies that the airport is already a } \\
\text { popular destination. The economies of scale } \\
\text { enjoyed on routes to and from these busy } \\
\text { airports would mean lower transportation costs } \\
\text { on the node-hub links }\end{array}$ & $\begin{array}{l}\text { Furness' method of a } \\
\text { double-constrained } \\
\text { gravity model based on } \\
\text { world bank data }\end{array}$ \\
\hline Shortest paths & Lowest total sector distance for the cluster & $\begin{array}{l}\text { 50-by-50 distance matrix } \\
\text { from an on-line airport } \\
\text { mileage calculator }\end{array}$ \\
\hline Centrality of the hub & $\begin{array}{l}\text { Shortest distance from the geographical } \\
\text { centre of the hub. The hub airport should be } \\
\text { conveniently located geographically, so that } \\
\text { it is well connected as a hub and does not } \\
\text { inconvenience passengers }\end{array}$ & $\begin{array}{l}\text { 50-by-50 distance matrix } \\
\text { from an on-line airport } \\
\text { mileage calculator }\end{array}$ \\
\hline $\mathrm{N}-\mathrm{H}$ costs & Cheapest node-hub costs & Eqns (1) and (2) \\
\hline Network costs & Lowest total network costs & Eqn (3) $[4]$ \\
\hline
\end{tabular}


The MCDA method allows for decision makers to weigh each of these alternatives based on the overall desired effect. In this study, each of the alternatives is weighted equally, based on the lack of factual evidence that one criterion has a higher effect on the suitability of a hub location option over another hub.

Therefore, the methodology that will be adapted in the four steps is summarised below.

1. Decision problem: To locate the four cheapest hub location option within the African continent.

2. Assessing possible impacts of each alternative: The possible impact of each of these alternatives is in gauging the suitability and cost effectiveness of the hub location option for the H\&S network. These are differentiated into the functional, locational and operational criteria.

3. Determine preferences (values) of decision makers: Based on the various findings in literature the preference values are also linked to designing a cost effective H\&S network, summarised in Table 2.

4. Evaluate and compare alternatives: The alternative hub airports will be assigned individually for each criterion. The airport with the highest total index criterion value will be chosen as the hub airport.

\section{EVALUATE AND COMPARE ALTERNATIVES}

All the international airports used in the database of the cost model were analysed using the criterion set out in Table 3 . The indexes are calculated and summarised for the airports within each of the clusters that have the highest indexes.

Table 3: Hub location evaluation.

\begin{tabular}{|c|c|c|c|c|c|c|c|c|c|}
\hline \multirow{2}{*}{$\frac{\text { Region }}{\text { Airport code }}$} & \multicolumn{3}{|c|}{ Northern cluster } & \multicolumn{2}{|c|}{ Southern cluster } & \multicolumn{2}{|c|}{ Eastern cluster } & \multicolumn{2}{|c|}{ Western cluster } \\
\hline & FEZ & ALG & CAI & JNB & HRE & NBO & $\mathrm{ADD}$ & LOS & DKR \\
\hline Country & Morocco & Algeria & Egypt & $\begin{array}{l}\text { South } \\
\text { Africa }\end{array}$ & Zimbabwe & Kenya & Ethiopia & Nigeria & Senegal \\
\hline $\begin{array}{l}\text { Infrastructural } \\
\text { capacity }\end{array}$ & 0.250 & 0.500 & 1.000 & 1.000 & 0.333 & 1.000 & 0.500 & 1.000 & 1.000 \\
\hline Airport capacity & 0.023 & 0.273 & 1.000 & 1.000 & 0.294 & 1.000 & 0.778 & 0.500 & 1.000 \\
\hline Airlines served & 0.327 & 0.286 & 1.000 & 1.000 & 0.214 & 1.000 & 0.422 & 1.000 & 0.778 \\
\hline $\begin{array}{l}\text { Passenger } \\
\text { numbers }\end{array}$ & 1.000 & 1.000 & 0.935 & 1.000 & 0.072 & 0.879 & 1.000 & 1.000 & 0.077 \\
\hline $\begin{array}{l}\text { Centrality/ } \\
\text { shortest path }\end{array}$ & 0.942 & 1.000 & 0.616 & 0.975 & 1.000 & 1.000 & 0.924 & 1.000 & 0.728 \\
\hline $\begin{array}{l}\text { Node-hub (costs } \\
\text { per pass US\$) }\end{array}$ & 0.509 & 1.000 & 0.759 & 1.000 & 0.266 & 0.953 & 1.000 & 1.000 & 0.712 \\
\hline $\begin{array}{l}\text { Network costs } \\
\text { (US\$) }\end{array}$ & 0.509 & 1.000 & 0.267 & 1.000 & 0.857 & 0.838 & 0.850 & 1.000 & 0.750 \\
\hline \multirow[t]{2}{*}{ Total index } & 3.559 & 5.058 & 5.576 & 6.975 & 3.036 & 6.671 & 5.474 & 6.500 & 5.045 \\
\hline & \multicolumn{3}{|c|}{$\begin{array}{l}\text { Cairo International } \\
\text { Airport }(\mathrm{CAI})\end{array}$} & \multicolumn{2}{|c|}{$\begin{array}{l}\text { O R Tambo Airport } \\
\text { (JNB) }\end{array}$} & $\begin{array}{l}\text { Jomo K } \\
\text { Airport }\end{array}$ & (NBO) & \multicolumn{2}{|c|}{$\begin{array}{l}\text { Lagos } \\
\text { International } \\
\text { Airport (LOS) }\end{array}$} \\
\hline
\end{tabular}


Based on the evaluation criteria, for each cluster the airport with the highest total index is the most suitable hub option in the cluster. In the north, south, east and west, all the airports with highest airport capacity and passenger numbers are chosen as the suitable hubs.

The usefulness of this study is that it is able to prove that MCDA is a simple useful tool that can be used to further explore the ways in which an optimally efficient hub network design, specific to sparse markets. MCDA provides a solution to the hub-location problem that can incorporate elements that range from operational to functional while preserving the methodology of each individual criterion, and furthermore this criterion can be ranked in order of importance, so as to come to an appropriate decision.

The major findings in this study shows that because Africa has a sparse network, with a few role players, the choice in hub location options relies greatly on the cost of routing passengers through the hub airport. The hub airport should be near the economic heart of the region so that it is able to nurture economic growth through employment, infrastructure and development. MCDA is shown to be a useful tool whose only limitation is the assumed uniform weighting of the different criteria for the region based on lack of suitable data.

\section{REFERENCES}

[1] Chingosho, E., African Airlines in the Era of Liberalization; Surviving the Competitive Jungle. E-Book, ISBN 9966-05-011-6, 2005.

[2] Button, K., Lall, S., Stough, R. \& Trice, M., Debunking some common myths about airport hubs. Journal of Air Transport Management, 8, pp. 177-188, 2002. doi:10.1016/S0969-6997(02)00002-9

[3] CMISRO (Center for Mathematical and Information Sciences), Operations Research Hub Location Report. Australia, 2003. http://www.cmis.csiro.au/or/hubLocation/ accessed 3/02/04.

[4] Ssamula, B., Strategies to Design a Cost-effective Hub Network for Sparse Air Travel Demand in Africa. PhD Thesis, University of Pretoria, South Africa, 2008.

[5] Boland, N., Krishnamoorthy, M., Ernst, A.T. \& Ebery, J., Preprocessing and cutting for multiple allocation hub location problems. European Journal of Operational Research, 155(3), pp. 638-653, 2004. doi:10.1016/S0377-2217(03)00072-9

[6] Campbell, J.F., Hub location and the $\rho$-hub median problem. Operations Research, 44, pp. 923-935, 1996. doi:10.1287/opre.44.6.923

[7] Schnell, M.C.A. \& Huschelrath, K., Existing and new evidence on the effects of airline hubs. International Journal of Transport Economics, XXXI(1), pp. 99-121, 2004.

[8] Morrell, P. \& Lu, C., The environmental cost implication of hub-hub versus hub by-pass flight networks. Transportation Research Part D, 12, pp. 143-157, 2007. doi:10.1016/j. $\operatorname{trd} .2007 .01 .008$

[9] Tecle, A. \& Duckstein, L., Concepts of multicriterion decision making. Multicriteria Analysis in Water Resources Management, eds J.J. Bogardi \& H.P. Nachtnebel, UNESCO: Paris, pp. 33-62, 1994.

[10] Pieterson, K., Multiple criteria decision analysis (MCDA); a tool to support sustainable management of groundwater resources in South Africa. Water SA, 32(2), pp. 119-128, 2006. ISSN 0378-4738.

[11] Belton, V. \& Stewart, T.J., Multiple Criteria Decision Analysis - An Integrated Approach, Kluwer Academic Publishers: Boston/Dordrecht/London, 2002.

[12] Keeney, R.L., Decision analysis: an overview. Operations Research, 30(5), pp. 803-838, 1982. doi:10.1287/opre.30.5.803 
[13] O'Kelly, M.E. \& Bryan, D., Hub location with flow economies of scale. Transportation Research Part B, 32(8), pp. 605-616, 1998. doi:10.1016/S0191-2615(98)00021-6

[14] Ssamula, B., Analysing aircraft selection for route operating cost for short-haul routes. Journal of the South African Institute for Civil Engineers (SAICE), 48(2), pp. 2-9, 2006.

[15] Swan, W.M. \& Adler, N.,Aircraft trip cost parameters: a function of stage length and seat capacity. Transportation Research Part E, 42, pp. 105-115, 2006. doi:10.1016/j.tre.2005.09.004

[16] Topcuoglu, H., Corut, F., Ermis, M. \& Yilmaz, G., Solving the uncapacitated hub location problem using genetic algorithms. Computers \& Operations Research, 32(4), pp. 967-984, 2005. doi:10.1016/j.cor.2003.09.008

[17] Klincewicz, J.G., A dual algorithm for the uncapacitated hub location problem. Location Science, 4, pp. 173-184, 1996.

[18] Doganis, R., The Airline Industry in the 21st Century, 1st edn, Routledge: London, 2001.

[19] Ssamula, B., Developing a Cost Model for Running an Airline Service. MEng Dissertation, University of Pretoria, South Africa, 2004. 